\title{
Retinal Capillary Hemangioma
}

National Cancer Institute

\section{Source}

National Cancer Institute. Retinal Capillary Hemangioma. NCI Thesaurus. Code C4920.

A capillary hemangioma arising from the retina. 